ARTIGO ORIGINAL

\title{
Avaliação genética em sementes de Stryphnodendron pulcherrimum sob diferentes níveis de temperatura
}

\author{
Genetic characterization of Stryphnodendron pulcherrimum seeds under \\ different temperature levels
}

\author{
Ivinne Nara Lobato dos Santos ${ }^{1}$ (D), Maria Teresa Gomes Lopes ${ }^{1}$ (D), Mágno Sávio Ferreira Valente ${ }^{2}$ (1), \\ Manuel de Jesus Vieira Lima Júnior ${ }^{1}$ (10), Therezinha de Jesus Pinto Fraxe ${ }^{1}$ (1) \\ ${ }^{1}$ Universidade Federal do Amazonas - UFAM, Manaus, AM, Brasil \\ ${ }^{2}$ Instituto Federal do Amazonas - IFAM, Presidente Figueiredo, AM, Brasil
}

Como citar: Santos, I. N. L., Lopes, M. T. G., Valente, M. S. F., Lima Júnior, M. J. V., \& Fraxe, T. J. P. (2020). Avaliação genética em sementes de Stryphnodendron pulcherrimum sob diferentes níveis de temperatura. Scientia Forestalis, 48(125), e3092. https://doi.org/10.18671/scifor.v48n125.06

\begin{abstract}
Resumo
Os objetivos deste trabalho foram estimar parâmetros genéticos em caracteres de sementes de Stryphnodendron pulcherrimum sob diferentes temperaturas e indicar matrizes superiores para a produção de mudas, a fim de subsidiar estratégias para a domesticação e melhoramento da espécie. Foram coletadas sementes de 21 matrizes da espécie S. pulcherrimum originárias do município de Apuí, Amazonas. O delineamento utilizado foi o inteiramente casualizado, com quatro repetições de 25 sementes. Os testes de germinação foram conduzidos em temperaturas de 25,30 e $35{ }^{\circ} \mathrm{C}$, com avaliação diária durante 20 dias. Foram realizadas análises de variância individual e conjunta e estimados parâmetros genéticos e ganho de seleção para a porcentagem de germinação, tempo médio de germinação e os índices de sincronização e de velocidade de germinação. A análise biométrica das sementes também foi considerada. A presença de variabilidade genética e altos valores de herdabilidade e acurácia seletiva (> 69\%) para todos os caracteres de germinação sugerem que o valor fenotípico pode fornecer uma medida confiável para seleção de genótipos superiores. A maior porcentagem de germinação foi obtida em temperatura de $25{ }^{\circ} \mathrm{C}(92 \%)$, havendo decréscimo de sementes geminadas e tempo médio de germinação com o aumento da temperatura. Correlações significativas entre os caracteres e no sentido favorável a seleção torna o processo seletivo mais simples, com as progênies 11, 14 e 15 apresentando boas características de germinação para condições de temperaturas mais amenas e elevadas, sendo indicadas para programas de conservação, melhoramento e produção de mudas da espécie.
\end{abstract}

Palavras-chave: Barbatimão; Teste de progênie; Germinação; Ganho de seleção; Parâmetros genéticos.

\begin{abstract}
The aims of this work were to estimate genetic parameters in Stryphnodendron pulcherrimum seeds under different temperatures and to indicate superior matrices for the production of seedlings, in order to subsidiary strategies for the domestication and breeding of the species. Seeds were collected from 21 matrices of S. pulcherrimum species from the city of Apuí, Amazonas. The experiment was completely randomized, with four replications of 25 seeds. The germination test was conducted at temperatures of 25,30 and $35{ }^{\circ} \mathrm{C}$, during 20 days. Individual and joint analysis of variance was carried out and the genetic parameters and selection gains estimated for the following characters: percentage of germination, mean germination time, and the synchronization and germination speed indexes.
\end{abstract}

Fonte de financiamento: Conselho Nacional de Desenvolvimento Científico e Tecnológico - CNPq - Concessão de bolsa de estudo (Processo: 133403/2017-3).

Conflito de interesse: Nada a declarar.

Autor correspondente: magnosavio@yahoo.com.br

Recebido em: 1 outubro 2018.

Aceito em: 7 maio 2019.

Editor: Francides Gomes da Silva Júnior.

(i) Este é um artigo publicado em acesso aberto (Open Access) sob a licença Creative Commons Attribution, que permite uso, distribuição e reprodução em qualquer meio, sem restrições desde que o trabalho original seja corretamente citado. 
Biometric analysis of the seeds was also considered. The presence of genetic variability and high heritability values and selective accuracy (> 69\%) for all germination traits suggest that the phenotypic value may provide a reliable measure for the selection of superior genotypes. The highest percentage of germination was obtained at the temperature of $25^{\circ} \mathrm{C}(92 \%)$, with decreasing germinated seeds and mean germination time with increasing temperature. Significant correlations favorable for selection among the characters make the selection process simpler, with progenies 11, 14 and 15 presenting good germination for milder and higher temperature conditions, being indicated for conservation programs, breeding and seedling production of the species.

Keywords: Barbatimão; Progeny test; Germination; Selection gain; Genetic parameters.

\section{INTRODUÇÃO}

Stryphnodendron pulcherrimum (Wild.) Hochr. é uma espécie pertencente à família Fabaceae, sendo conhecida popularmente como barbatimão, paricazinho, paricarana, jubarbatimão, juerana-branca e caubi. A espécie é normalmente encontrada na Amazônia e no sul da Bahia nas florestas Amazônica e Atlântica. Também está presente nas Guianas, Venezuela e Colômbia (Lorenzi, 1992; Silva et al., 2015).

De acordo com Lorenzi (1992), é uma espécie pioneira que ocorre preferencialmente em florestas secundárias, sendo recomendada para reflorestamento ecológico. Sua madeira é moderadamente resistente e tem sido empregada na fabricação de compensados, paletes, lenha e carvão (Pereira et al, 2016). Além disso, é utilizada com sucesso como ornamental e na apicultura (Monteiro \& Ramalho, 2010). Pesquisas ainda relatam a atividade antibacteriana de extratos da planta contra patógenos orais (Castilho et al., 2013) e como boa fonte de antioxidantes (Lins Neto et al., 2016). Também é grande o número de trabalhos em espécies do gênero que relatam o uso da casca do caule para cicatrização de feridas e no tratamento de doenças infecciosas e de distúrbios inflamatórios (Souza-Moreira et al., 2018)

S. pulcherrimum produz anualmente grande quantidade de sementes e possui importância para recuperação de áreas degradadas, no entanto, existe dificuldade de obtenção de mudas devido à presença de dormência tegumentar e germinação desuniforme (Pereira et al, 2016). Tomaz et al. (2018) citam que diversas espécies florestais nativas têm evitado o desaparecimento através de programas de reflorestamento, mas que esta atividade tem sido limitada por dificuldades na produção de mudas, em especial pela falta de informações básicas sobre condições ideais de germinação de sementes.

No gênero Stryphnodendron, que apresenta semente dura, estudos mostram que a impermeabilidade do tegumento à água pode ser superada com mecanismos de escarificação mecânica ou ácida das sementes (Lemus Filho et al., 1997; Pereira et al, 2016). Todavia, a germinação desuniforme ainda é um problema limitante para produção de mudas em S. pulcherrimum, necessitando de maiores informações do processo germinativo sob diferentes condições de cultivo.

Dentre os diversos fatores que afetam diretamente a germinação de sementes, a temperatura está entre os de maior influência (Carvalho \& Nakagawa, 2012). Para espécies florestais amazônicas, normalmente as temperaturas ótimas de germinação são um pouco mais elevadas quando comparadas com as outras regiões do Brasil, uma vez que a região amazônica apresenta clima mais quente na época propícia para a germinação natural.

Neste cenário, muito tem se discutido sobre mudanças climáticas globais e quais os efeitos que estas poderão causar na humanidade e nos ecossistemas em geral, mas poucos são os estudos que visam antecipar estas mudanças, a exemplo de aumentos nas temperaturas médias, e tentar evitar danos irreversíveis aos ecossistemas. Diante deste fato, faz-se necessário verificar qual seria o efeito de temperaturas elevadas na germinação de sementes de S. pulcherrimum, sendo também importante a identificação de matrizes superiores para tais condições ambientais.

Informações a respeito da variabilidade genética de populações naturais e a caracterização dos padrões de herança de caracteres de germinação da espécie devem ser priorizadas para que seja possível definir critérios de seleção e recombinação genética com vistas à produção de materiais elites (Cruz et al., 2014). Desta forma, caracteres como germinação rápida e uniforme são características desejáveis na formação de mudas para o 
estabelecimento de plantios e estas devem estar presentes em genótipos superiores da espécie.

Adicionalmente, a estimativa de parâmetros genéticos e fenotípicos em progênies, como herdabilidade, correlações entre caracteres e ganhos com a seleção, possibilitam a escolha de métodos e caracteres utilizados nas etapas iniciais e avançadas de programas de melhoramento, permitindo ainda, estudar mecanismos, valores genéticos e variabilidade de um caráter (Cruz et al., 2014). Estudos desta natureza em caracteres de germinação podem ser observados em outras espécies florestais amazônicas (Nascimento Júnior et al., 2016; Tomaz et al., 2018), porém em S. pulcherrimum estes dados são ainda inexistentes e facilitariam a obtenção de mudas e forneceriam diretrizes para a seleção de matrizes superiores para compor lotes de sementes. Além do que possibilita auxiliar na domesticação e conservação de seu germoplasma (Santos et al., 2014).

Diante do exposto, os objetivos deste trabalho foram estimar parâmetros genéticos em caracteres de sementes de S. pulcherrimum sob diferentes temperaturas e indicar matrizes superiores para a produção de mudas, a fim de subsidiar estratégias para a domesticação e melhoramento da espécie.

\section{MATERIAL E MÉTODOS}

O material genético utilizado para este estudo foi obtido a partir de uma população nativa de S. pulcherrimum localizada no município de Apuí no estado do Amazonas. Foram identificadas 21 matrizes de polinização aberta, sendo coletados no mínimo 150 frutos de cada indivíduo respeitando-se uma distância mínima de $100 \mathrm{~m}$ entre plantas. Os frutos coletados receberam identificação com a mesma numeração da matriz de origem e, após beneficiamento, as sementes passaram por secagem natural com posterior armazenamento em sacos plásticos selados e acondicionamento em câmara fria a $18{ }^{\circ} \mathrm{C}$ até o início do experimento.

Os testes de germinação das sementes foram realizados em câmaras tipo BOD em temperaturas (ambientes) de 25,30 e $35^{\circ} \mathrm{C}$. A variação da temperatura não foi superior a $2{ }^{\circ} \mathrm{C}$ em um período de 24 horas, segundo recomendações de Brasil (2013). O fotoperíodo de doze horas por dia correspondeu ao período luminoso à temperatura mais elevada, em germinador de câmara, com lâmpadas fluorescentes de 20W. A semeadura foi realizada em papel de germinação tipo germitest.

Devido a um mecanismo de dormência comum no gênero Strypnodendron, como exemplo da impermeabilidade do tegumento à água, foi adotado um tratamento pré-germinativo com uso da escarificação mecânica segundo Lemus Filho et al. (1997).

O delineamento utilizado foi o inteiramente casualizado, com quatro repetições de 25 sementes, totalizando 100 sementes por matriz. Todos os indivíduos foram avaliados diariamente durante 20 dias.

As sementes de $S$. pulcherrimum foram avaliadas a partir dos caracteres: a) Porcentagem de germinação (PG) - considerou-se germinadas as sementes que emitiram raiz primária, com o seu valor correspondendo à porcentagem de sementes germinadas até o término do experimento no $20^{\circ}$ dia após semeadura. Os resultados foram expressos em porcentagem média com base no número de plântulas normais (Brasil, 2009); b) Tempo Médio de germinação (TMG) - obtido por meio de contagens diárias das sementes germinadas até o fim do experimento e calculado através da fórmula $T M G=\Sigma n_{i} t_{i} / \Sigma n_{i}$, em que, $n_{i}$ é o número de sementes germinadas no intervalo de cada contagem e $t_{i}$ é o número de dias da semeadura e a i-ésima contagem, sendo os resultados expressos em dias; c) Índice de sincronização de germinação (ISG) - foi determinado segundo a formula $I S G=-\Sigma f_{i} \log f_{i}$, onde $f_{i}$ é a frequência relativa de germinação e; d) Índice de Velocidade de Germinação (IVG) - calculado pelo somatório do número de sementes germinadas a cada dia $\left(n_{i}\right)$, dividido pelo número de dias decorridos entre a semeadura e a germinação $\left(t_{i}\right)$, dado pela fórmula $I V G=\Sigma n_{i} t_{i}$.

Caracteres biométricos das sementes também foram considerados. Para tal, com o auxílio de um paquímetro, trinta sementes de cada matriz foram mensuradas com base no 
seu comprimento $(\mathrm{mm})$, largura $(\mathrm{mm})$ e espessura $(\mathrm{mm})$. O peso úmido das sementes foi obtido em balança de precisão $(0,001 \mathrm{~g})$ e o teor de água determinado pelo método de estufa regulada a $105^{\circ} \mathrm{C} \pm 3^{\circ} \mathrm{C}$ por 24 horas (Brasil, 2009).

Os dados obtidos para os caracteres de germinação foram submetidos ao teste de normalidade (teste de Lilliefors) para verificar a necessidade de transformação dos mesmos. Posteriormente, o teste de Cochram foi realizado para confirmar ou não a homogeneidade de variância e a necessidade de ajuste dos graus de liberdade, permitindo a análise conjunta dos dados nas três temperaturas (ambientes) de avaliação.

Os parâmetros genéticos estimados foram a herdabilidade com base na média de progênies, a acurácia seletiva, o coeficiente de variação genético, o coeficiente de variação experimental e a razão entre o coeficiente de variação genético e o coeficiente de variação ambiental, conforme Cruz et al. (2014). Adicionalmente, foram estimadas as correlações fenotípicas e genotípicas para todos os caracteres de germinação. Foram selecionadas as melhores progênies com base na seleção direta e a partir do índice de seleção de Mulamba \& Mock (1978), com mesmo peso econômico para todos os caracteres. A pressão de seleção utilizada foi de $33,33 \%$.

Para os caracteres biométricos de sementes foi estimado o coeficiente de repetibilidade com base em componentes principais e matriz de variâncias e covariâncias fenotípicas, além do número mínimo de medições necessário para predizer o valor real dos genótipos com base em um coeficiente de determinação de $80 \%$, conforme descrito em Valente et al. (2017).

Todas as análises estatísticas foram realizadas utilizando o programa Genes (Cruz, 2013).

\section{RESULTADOS E DISCUSSÃO}

A porcentagem de sementes germinadas foi decrescendo com o aumento da temperatura, indo de $92,85 \%$ no ambiente de $25{ }^{\circ} \mathrm{C}$ à $72,90 \%$ para o ambiente de $35^{\circ} \mathrm{C}$ (Figura 1). Estes valores foram superiores aos obtidos por Silva et al. (2015) avaliando mesma espécie, da qual os autores realizando a quebra de dormência das sementes com ácido sulfúrico, observaram uma porcentagem de germinação de 65 e 55\% nas avaliações em temperaturas de 25 e $30^{\circ} \mathrm{C}$, respectivamente.
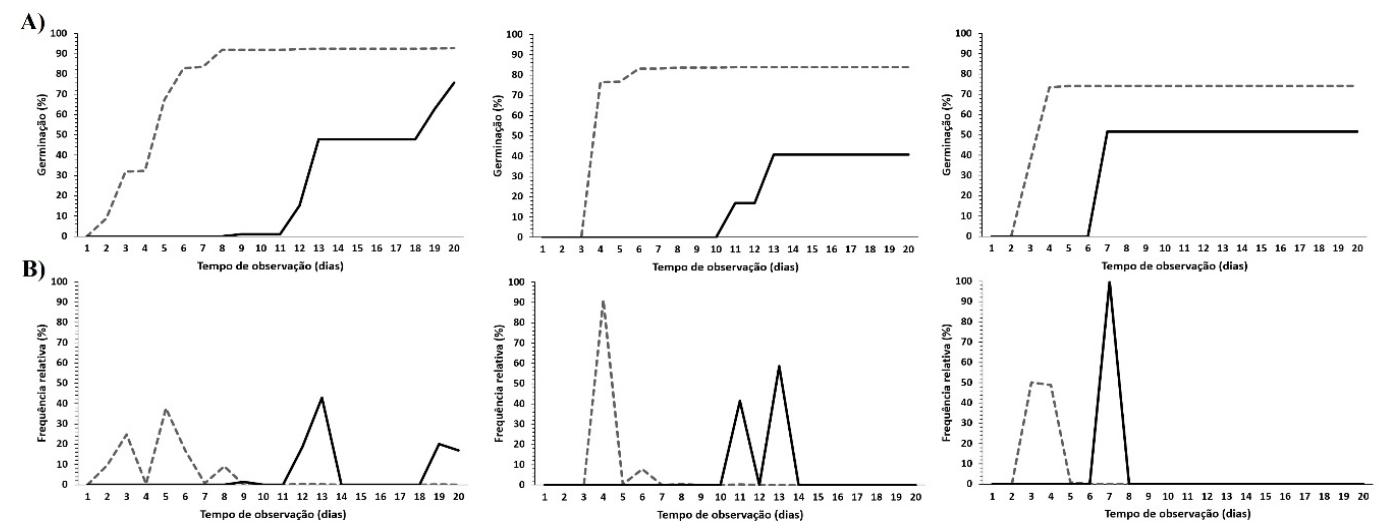

Figura 1. Porcentagem média de germinação $(A)$ e frequência relativa de germinação $(B)$ de 21 progênies de $S$. pulcherrimum submetidas às temperaturas de 25,30 e $35^{\circ} \mathrm{C}$.

Na Figura 1 é possível observar que o início de germinação se deu entre o segundo e terceiro dia após a semeadura e, neste caso, o aumento da temperatura conduziu a um menor tempo médio de germinação. Em geral, baixas temperaturas proporcionam germinação mais lenta em espécies tropicais pois o processo germinativo envolve enzimas cuja atividade máxima é geralmente acima de $25{ }^{\circ} \mathrm{C}$ (Carvalho \& Nakagawa, 2012), sendo comum na família Fabaceae a germinação iniciar no intervalo de 2 a 15 dias após o plantio. Em Stryphnodendron adstringens as temperaturas ótimas de germinação ficam entre 
25 e $35^{\circ} \mathrm{C}$, com alguns trabalhos apresentando o percentual de sementes germinadas próximo a $86 \%$ após quebra de dormência por ácido sulfúrico (Martins et al., 2008) e de $88 \%$ com o uso de escarificação mecânica (Freitas et al., 2013).

O período para formação de plântulas de $S$. pulcherrimum iniciou-se no $6^{\circ}$ dia após início do experimento, em temperatura de $35^{\circ} \mathrm{C}$ e, um pouco mais tardia, a partir do $10^{\circ} \mathrm{dia}$, para as temperaturas de 25 e $30^{\circ} \mathrm{C}$ (Figura 1). Resultados semelhantes aos obtidos por Pereira et al. (2016) para a mesma espécie, onde a emergência de plântulas iniciou entre o $6^{\circ}$ e $9^{\circ}$ dias após semeadura.

Sementes de S. pulcherrimum apresentaram um teor de água médio de 4,64\%, sugerindo tolerância ao dessecamento. Com base no resultado do estudo, o comportamento das sementes da espécie apresenta característica ortodoxa. No entanto, há necessidade de estudos relacionados a viabilidade das sementes para validar esta classificação.

De acordo com o teste de Lilliefors, os dados (resíduos) para porcentagem de germinação não apresentaram normalidade e, deste modo, foram transformados em arco seno $\sqrt{x / 100}$, com $x$ correspondendo à porcentagem de sementes germinadas.

Nas análises de variância individual observou-se efeito significativo $(P<0,01$ ou $P<0,05)$ dos genótipos nas três temperaturas avaliadas, demonstrando que as progênies possuem variabilidade genética para todos os caracteres de germinação (Tabela 1). A temperatura de $25{ }^{\circ} \mathrm{C}$ conduziu a maior porcentagem de germinação, estando de acordo com a recomendação de Rodrigues et al. (2008) para a maioria das espécies florestais tropicais, cuja temperatura constante de $25{ }^{\circ} \mathrm{C}$ encontra-se na faixa ótima para germinação. Em estudo realizado por Lima Júnior (2016) no Centro de Sementes Nativas da Amazônia (CSNAM), a fim de verificar a temperatura ideal de germinação para 50 espécies florestais e subtropicais consideradas prioritárias, observou que as temperaturas constantes de $25^{\circ} \mathrm{C} \mathrm{e}$ $30{ }^{\circ} \mathrm{C}$ foram as ideais para $58 \%$ e $32 \%$ das espécies estudadas, respectivamente.

Tabela 1. Quadrado médio de genótipos (QMG) e parâmetros genéticos para a porcentagem de germinação (PG), tempo médio de germinação (TMG), índice de sincronização de germinação (ISG) e índice de velocidade de germinação (IVG), avaliados em sementes de S. pulcherrimum em ambientes de 25,30 e $35^{\circ} \mathrm{C}$.

\begin{tabular}{|c|c|c|c|c|c|c|c|c|}
\hline \multirow{2}{*}{ Caracteres } & \multirow{2}{*}{ Ambientes } & \multirow{2}{*}{ QMG } & \multirow{2}{*}{ Média Geral' } & \multicolumn{5}{|c|}{ Parâmetros Genéticos ${ }^{2}$} \\
\hline & & & & $h_{p m}^{2}$ & $A c c$ & $\mathrm{CVg}_{g}^{\circ}$ ) ) & $\left.\mathrm{CV}_{\text {eq }}\right)$ & $C V_{r}$ \\
\hline \multirow{3}{*}{ PG } & $25^{\circ} \mathrm{C}$ & $0,0472 * *$ & $1,4396(92,85)$ & 0,5744 & 0,7579 & 6,1001 & 10,5007 & 0,5809 \\
\hline & $30^{\circ} \mathrm{C}$ & $0,1042 * *$ & $1,1966(83,90)$ & 0,8162 & 0,9034 & 12,1876 & 11,5671 & 1,0536 \\
\hline & $35^{\circ} \mathrm{C}$ & $0,1038 * *$ & $1,0433(72,90)$ & 0,8180 & 0,9044 & 13,9648 & 13,1750 & 1,0599 \\
\hline \multirow{3}{*}{ TMG } & $25^{\circ} \mathrm{C}$ & $1,9339 * *$ & 4,7925 & 0,7775 & 0,8818 & 12,7935 & 13,6872 & 0,9347 \\
\hline & $30^{\circ} \mathrm{C}$ & $0,2580 *$ & 3,2253 & 0,4756 & 0,6896 & 5,4309 & 11,4053 & 0,4762 \\
\hline & $35^{\circ} \mathrm{C}$ & $0,2000 * \star$ & 2,5315 & 0,7994 & 0,8941 & 7,8980 & 7,9128 & 0,9981 \\
\hline \multirow{3}{*}{ ISG } & $25^{\circ} \mathrm{C}$ & $1,9689 * \star$ & 0,7091 & 0,9714 & 0,9856 & 97,5168 & 33,4449 & 2,9157 \\
\hline & $30^{\circ} \mathrm{C}$ & $0,2862 * \star$ & 0,3322 & 0,5860 & 0,7655 & 61,6458 & 103,6305 & 0,5949 \\
\hline & $35^{\circ} \mathrm{C}$ & $0,2021 * \star$ & 0,7501 & 0,7327 & 0,8560 & 25,6520 & 30,9904 & 0,8277 \\
\hline \multirow{3}{*}{ IVG } & $25^{\circ} \mathrm{C}$ & 8,0901 ** & 5,597 & 0,8587 & 0,9267 & 23,5458 & 19,1009 & 1,2327 \\
\hline & $30^{\circ} \mathrm{C}$ & $4,5479 * \star$ & 6,7379 & 0,8440 & 0,9187 & 14,5387 & 12,5010 & 1,1630 \\
\hline & $35^{\circ} \mathrm{C}$ & $12,7426 * *$ & 7,5664 & 0,8796 & 0,9379 & 22,1230 & 16,3714 & 1,3513 \\
\hline
\end{tabular}

$\star \star ; * p<0,01, p<0,05$, respectivamente, pelo teste F. ${ }^{1}$ Média dos dados de PG transformados (arcoseno da raiz de $\mathrm{x} / 100$ ) e original em porcentagem; ${ }^{2} \hat{h}_{p m}^{2}=$ herdabilidade da média de progênies; $A c c=$ acurácia da seleção de progênies; $C V_{g}=$ coeficiente de variação genotípica entre progênies; $C V_{e}=$ coeficiente de variação experimental; $C V_{r}=C V_{g} / C V_{e}$ : coeficiente de variação relativa. 
Durante as avaliações todas as sementes que não germinaram nas temperaturas de 30 e $35^{\circ} \mathrm{C}$ apresentaram-se totalmente deterioradas por fungos (Aspergillus e Rhizopus). Estas sementes tiveram um processo de deterioração acelerado, com maior destaque para a temperatura de $35^{\circ} \mathrm{C}$, com lixiviação do conteúdo celular, criando um ambiente propício para o desenvolvimento de micro-organismos, o que ajuda a justificar a menor germinação nestas temperaturas.

$\mathrm{O}$ índice de velocidade de germinação foi menor para o ambiente de $25{ }^{\circ} \mathrm{C}$, apresentando o valor médio de 5,59 e tempo médio de germinação de 4,79 (dias). Já o ambiente de $35{ }^{\circ} \mathrm{C}$ apresentou o maior IVG $(7,56)$ e menor TMG $(2,53$ dias). Tomaz et al. (2018), em estudo com Ormosia excelsa (Fabaceae), também verificaram uma maior precocidade e velocidade de germinação com o aumento da temperatura (de 4 a 8 dias para $30{ }^{\circ} \mathrm{C}$ e entre 2 a 7 dias para $35^{\circ} \mathrm{C}$ ).

Em relação ao índice de sincronização de germinação, foi observado que o ambiente de $30{ }^{\circ} \mathrm{C}$ apresentou o valor mais favorável (0,3322), estando de acordo com o postulado por Rickli et al. (2014) que indica quanto mais próximo de zero maior é a sincronia na germinação.

Duarte et al. (2015) usando o substrato de papel, aliado à temperatura de $30{ }^{\circ} \mathrm{C}$, concluíram que esta era a combinação mais eficiente para a sincronização da germinação de sementes de Albizia edwallii (Fabaceae), fato também observado por Rickli et al. (2014) e Tomaz et al. (2018) em sementes de Vochysia bifalcata e Ormosia excelsa, respectivamente. Pode-se inferir que na temperatura de $30{ }^{\circ} \mathrm{C}$ a amostra de semente é "acionada" para germinar menos vezes do que nas temperaturas de 25 e $35^{\circ} \mathrm{C}$, promovendo assim a maior sincronia, já que uma única semente germinada em um dia pode afetar a sincronia de germinação em toda uma amostra (Santana \& Ranal, 2000).

Devido à ampla variabilidade existente entre as progênies estudadas, aliado ao bom controle ambiental praticado, foram obtidos de médios a altos coeficientes de herdabilidade com base na média das progênies para todos os caracteres (Tabela 1). Os valores oscilaram entre 57,44 e $97,14 \%$ para o ambiente de $25^{\circ} \mathrm{C}$, entre 47,56 e $84,39 \%$ para o ambiente a $30{ }^{\circ} \mathrm{C}$ e entre 73,26 e $87,95 \%$ para $35^{\circ} \mathrm{C}$. Estes resultados apresentam-se como condição favorável à seleção, existindo a possibilidade de ganhos expressivos no processo de produção de mudas da espécie.

Nas fases iniciais e intermediárias de um programa de melhoramento é preferível que se tenha valores de acurácia próximos ou superiores a 70\% (Resende, 2007). Portanto, os valores de acurácia obtidos neste trabalho (variando de 69\% a 98\%) são promissores. Os ambientes com temperaturas de 25 e $35^{\circ} \mathrm{C}$ foram os de maior destaque, apresentando os valores mais elevados de herdabilidade e acurácia, além da razão entre CVg/CVe terem sido, em sua maioria, próximos ou superiores a unidade nestes ambientes, situação considerada ideal a seleção.

Com base na análise de variância conjunta dos ambientes (Tabela 2), verificou-se que a germinação média das sementes foi de 83,21\% com tempo médio de germinação de 3,51 dias, havendo diferença estatística nos três ambientes. Além disso, a interação genótipo e ambiente foi significativa para todos os caracteres avaliados, revelando que as temperaturas utilizadas influenciaram diferentemente na expressão destes. Diante desse cenário, as inferências sobre os genótipos foram efetuadas individualmente para cada ambiente (temperatura). 
Tabela 2. Quadrados médios de genótipo (QMG), de ambiente (QMA) e da interação Genótipo e Ambiente (QMGA) e parâmetros genéticos para a porcentagem de germinação (PG), tempo médio de germinação (TMG), índice de sincronização de germinação (ISG) e índice de velocidade de germinação (IVG) em sementes de S. pulcherrimum, estimados a partir da análise conjunta dos ambientes de 25,30 e $35^{\circ} \mathrm{C}$.

\begin{tabular}{|c|c|c|c|c|c|c|c|c|c|}
\hline \multirow{2}{*}{ Caracteres } & \multirow{2}{*}{ QMG } & \multirow{2}{*}{ QMA } & \multirow{2}{*}{ QMGA } & \multirow{2}{*}{$\begin{array}{l}\text { Média } \\
\text { Geral1 }\end{array}$} & \multicolumn{5}{|c|}{ Parâmetros Genéticos² } \\
\hline & & & & & $h_{p m}^{2}$ & $A c c$ & $C V_{g} / \%$ ) & $C V_{e}^{\%} \%$ ) & $C V_{r}$ \\
\hline PG & $0,1467 * \star$ & $1,9698 * *$ & $0,0542^{* *}$ & $\begin{array}{l}1,1965 \\
(83,21)\end{array}$ & 0,6301 & 0,7938 & 7,3359 & 11,6345 & 0,6305 \\
\hline TMG & $0,9591^{\text {ns }}$ & $112,6854 * *$ & $0,9882 * *$ & 3,5164 & 0,0000 & 0,0000 & 0,0000 & 17,3094 & 0,0000 \\
\hline ISG & $1,0800^{\text {ns }}$ & $4,4580 * *$ & $0,6887 * *$ & 0,5971 & 0,3623 & 0,6019 & 30,2383 & 46,2476 & 0,6538 \\
\hline IVG & $12,8873 *$ & $82,1320 * *$ & $6,2467 * *$ & 6,6338 & 0,5153 & 0,7178 & 11,2137 & 16,0169 & 0,7001 \\
\hline
\end{tabular}

ns; $* * ;$ não significativo, $p<0,01, p<0,05$, respectivamente, pelo teste $\mathrm{F}$. ${ }^{1}$ Média dos dados de PG transformados (arcoseno da raiz de $\mathrm{x} / 100$ ) e original em porcentagem; ${ }^{2} \hat{h}_{p m}^{2}=$ herdabilidade da média de progênies; $A c c=$ acurácia da seleção de progênies; $C V_{g}=$ coeficiente de variação genotípica entre progênies; $C V_{e}=$ coeficiente de variação experimental; $C V_{r}=C V_{g} / C V_{e}$ : coeficiente de variação relativa.

A porcentagem de germinação e o índice de velocidade de germinação foram os únicos caracteres que apresentaram variabilidade genética significativa entre os genótipos, sendo as estimativas de herdabilidade na análise conjunta em sua maioria inferiores às obtidas nas análises individuais. Inclusive a herdabilidade para TMG foi nula na análise conjunta, o que segundo Tomaz et al. (2018) pode ser explicado pelas condições satisfatórias dos ambientes testados, já que todos os genótipos apresentaram médias fenotípicas próximas e elevadas, além de reduzida variância ambiental, o que neste caso resultou na nulidade do valor de variância genotípica.

Com relação a associação entre os caracteres de germinação, o conhecimento da magnitude e sentido da alteração num caráter quando o outro correlacionado está sob seleção está representado na Tabela 3. Os maiores valores de correlação genética foram estimados no ambiente a $30{ }^{\circ} \mathrm{C}$, entre os caracteres PG e ISG $(r=-0,997)$, seguido de PG e TMG $(r=-0,996)$ e TMG e IVG $(r=-0,996)$. Neste caso, as correlações negativas apontam para uma situação benéfica, uma vez que há tendência de aumento da porcentagem de germinação com a diminuição do tempo médio de germinação e o aumento da porcentagem de germinação em sementes com maior sincronismo, além de menor tempo médio de germinação associado a uma maior velocidade de germinação. Este fato torna o processo seletivo mais simples, não necessitando de adoções de restrições na seleção para obtenção de ganhos no sentido desejado (Nascimento Júnior et al., 2016).

Tabela 3. Correlações fenotípicas ( $r F)$ e genotípicas $(r G)$ entre a porcentagem de germinação (PG), tempo médio de germinação (TMG), índice de sincronização de germinação (ISG) e índice de velocidade de germinação (IVG) em sementes de S. pulcherrimum, avaliadas em ambientes de 25,30 e $35^{\circ} \mathrm{C}$.

\begin{tabular}{|c|c|c|c|c|c|c|c|c|c|c|}
\hline \multirow{2}{*}{ Caracteres } & \multirow{2}{*}{$r$} & \multicolumn{3}{|c|}{ Ambiente de $25^{\circ} \mathrm{C}$} & \multicolumn{3}{|c|}{ Ambiente de $30^{\circ} \mathrm{C}$} & \multicolumn{3}{|c|}{ Ambiente de $35^{\circ} \mathrm{C}$} \\
\hline & & TMG & ISG & IVG & TMG & ISG & IVG & TMG & ISG & IVG \\
\hline \multirow{2}{*}{ PG } & $\mathrm{F}$ & 0,068 & $-0,633 * \star$ & $-0,075$ & $-0,712 * \star$ & $-0,740 * *$ & $0,966 * \star$ & $-0,518^{*}$ & 0,237 & $0,933 * *$ \\
\hline & G & $-0,027$ & $-0,886 * *$ & $-0,179$ & $-0,996 * *$ & $-0,997 * *$ & $0,992^{*}$ & $-0,668 *$ & 0,257 & $0,950 *$ \\
\hline \multirow{2}{*}{ TMG } & $\mathrm{F}$ & & 0,011 & $-0,948 * *$ & & $0,924 * \star$ & $-0,839 * *$ & & $-0,548 * *$ & $-0,782 * *$ \\
\hline & G & & $-0,006$ & $-0,993 * *$ & & $0,985^{*}$ & $-0,996 * *$ & & $-0,868 *$ & $-0,867 *$ \\
\hline \multirow{2}{*}{ ISG } & $\mathrm{F}$ & & & 0,138 & & & $-0,829 * \star$ & & & 0,368 \\
\hline & G & & & 0,148 & & & $-0,974^{*}$ & & & 0,479 \\
\hline
\end{tabular}

$\star \star ; * p<0,01, p<0,05$, respectivamente, pelo teste $\mathrm{t}$ (correlações fenotípicas) e pelo método de bootstrap com 5000 simulações (correlações genotípicas). 
Para o ambiente de $25^{\circ} \mathrm{C}$, as únicas correlações significativas foram estimadas entre PG e ISG $(r=-0,886)$ e TMG e IVG $(r=-0,993)$, ambas no sentido favorável a seleção. No ambiente de $35^{\circ} \mathrm{C}$, dentre as associações significativas, apenas a correlação entre TMG e ISG $(r=-0,868)$ apresentou resultado desfavorável à prática da seleção direta, indicando que uma redução no tempo médio de germinação resultaria em uma menor sincronização das sementes germinadas. Para os coeficientes de correlação fenotípica, o comportamento foi similar aos de correlação genética nos três ambientes.

Os ganhos de seleção estimados a partir da seleção direta foram maiores no ambiente à $25{ }^{\circ} \mathrm{C}$ (Tabela 4), exceto para a porcentagem de germinação $(5,13 \%)$, que teve seu maior valor no ambiente de $35{ }^{\circ} \mathrm{C}(13,04 \%)$. De modo geral, foi possível obter resultados satisfatórios em todos os caracteres avaliados, com ganhos mais expressivos sendo estimados para ISG nos três ambientes. Conforme já esperado e discutido anteriormente em relação a associações entre os caracteres, a seleção direta em um caráter conduziu, em sua maioria, a ganhos indiretos favoráveis nos demais.

Tabela 4. Estimativas de ganho genético e identificação das progênies selecionadas por seleção direta e indireta para a porcentagem de germinação (PG), tempo médio de germinação (TMG), índice de sincronização de germinação (ISG) e índice de velocidade de germinação (IVG) em sementes de S. pulcherrimum, avaliadas em ambientes de 25,30 e $35^{\circ} \mathrm{C}$.

\begin{tabular}{|c|c|c|c|c|c|c|c|}
\hline \multirow{2}{*}{ Caracteres } & \multirow{2}{*}{ Ambientes } & \multirow{2}{*}{$\begin{array}{c}\text { GS (\%) } \\
\text { Seleção Direta }\end{array}$} & \multicolumn{4}{|c|}{ Ganho de seleção indireto (\%) } & \multirow{2}{*}{ Progênies selecionadas } \\
\hline & & & PG & TMG & ISG & IVG & \\
\hline \multirow{3}{*}{ PG } & $25^{\circ} \mathrm{C}$ & 5,13 & --- & 2,03 & $-38,52$ & $-2,62$ & $14,21,6,16,1,4,17$ \\
\hline & $30^{\circ} \mathrm{C}$ & 11,83 & --- & $-2,60$ & $-41,03$ & 12,69 & $14,19,21,9,16,11,13$ \\
\hline & $35^{\circ} \mathrm{C}$ & 13,04 & --- & $-2,40$ & 1,96 & 18,08 & $19,11,15,14,21,18,1$ \\
\hline \multirow{3}{*}{ TMG } & $25^{\circ} \mathrm{C}$ & $-11,23$ & $-0,01$ & --- & 26,22 & 21,27 & $11,17,15,7,6,19,18$ \\
\hline & $30^{\circ} \mathrm{C}$ & $-2,92$ & 9,90 & --- & $-47,05$ & 11,99 & $15,19,21,11,9,7,14$ \\
\hline & $35^{\circ} \mathrm{C}$ & $-6,89$ & 9,14 & --- & 4,64 & 19,43 & $14,15,1,2,9,19,12$ \\
\hline \multirow{3}{*}{ ISG } & $25^{\circ} \mathrm{C}$ & $-90,31$ & 3,20 & 2,14 & --- & $-8,65$ & $8,14,21,5,9,15,16$ \\
\hline & $30^{\circ} \mathrm{C}$ & $-48,44$ & 8,90 & $-2,92$ & --- & 11,46 & $15,19,21,11,16,7,9$ \\
\hline & $35^{\circ} \mathrm{C}$ & $-26,88$ & 0,09 & 3,07 & --- & $-2,78$ & $10,20,16,17,15,21,14$ \\
\hline \multirow{3}{*}{ IVG } & $25^{\circ} \mathrm{C}$ & 21,53 & $-0,35$ & $-10,70$ & 43,74 & --- & $11,17,15,7,19,6,2$ \\
\hline & $30^{\circ} \mathrm{C}$ & 13,13 & 11,58 & $-2,84$ & $-47,22$ & --- & $19,14,9,21,16,11,15$ \\
\hline & $35^{\circ} \mathrm{C}$ & 21,52 & 11,90 & $-6,15$ & 5,83 & --- & $15,14,19,1,2,11,12$ \\
\hline
\end{tabular}

De acordo com Tomaz et al. (2018), a obtenção de altos ganhos seletivos deve ser acompanhada de satisfatória variabilidade genética para os caracteres de interesse, uma vez que o processo de coleta de sementes não consegue manter a diversidade genética de populações. Neste sentido, foram indicadas as sete melhores progênies (pressão de seleção de 33,33\%) para cada caractere e temperatura analisada, com destaque para as progênies 11, 14, 15 e 19, que tiveram indicação em pelo menos oito dos doze cenários avaliados.

Também foi tomado como critério de seleção o desempenho das progênies em relação aos resultados combinados de todos os caracteres de germinação. Para tal, foi utilizado o índice de seleção baseado em soma de ranks conforme Mulamba \& Mock (1978) (Tabela 5). De acordo com esta metodologia, as condições ideais de germinação conforme os resultados aqui apresentados se daria na temperatura de $25{ }^{\circ} \mathrm{C}$, cuja as progênies selecionadas seriam as $6,11,14,15,16,17$ e 21 . Em caso de ambientes com temperaturas mais elevadas, a exemplo de $35^{\circ} \mathrm{C}$, as progênies indicadas seriam as 1, 2, 9, 11, 14, 15 e 19. Novamente podemos observar que as progênies 11, 14 e 15 se mostraram superiores, sendo indicadas para cultivo nos dois ambientes. Se utilizadas como matrizes para compor lotes de sementes, é esperado que estas germinem rápido e uniformemente, resultando em 
menor tempo no viveiro e mudas uniformes, diminuindo custos e facilitando o calendário dos plantios em S. pulcherrimum.

Tabela 5. Estimativas de ganho genético e identificação das progênies selecionadas pelo índice de Mulamba \& Mock (1978) para a porcentagem de germinação (PG), tempo médio de germinação (TMG), índice de sincronização de germinação (ISG) e índice de velocidade de germinação (IVG) em sementes de $S$. pulcherrimum, avaliadas em ambientes de 25,30 e $35^{\circ} \mathrm{C}$.

\begin{tabular}{ccccc}
\hline Ambientes & Caracteres & GS (\%) & Progênies selecionadas & $\begin{array}{c}\text { Coincidência (\%) } \\
\text { Selecionados na seleção } \\
\text { direta e Índice de seleção }\end{array}$ \\
\hline $25{ }^{\circ} \mathrm{C}$ & PG & 4,22 & & 85,71 \\
& TMG & $-7,79$ & $15,17,6,11,14,21,16$ & 57,14 \\
& ISG & $-60,09$ & & 57,14 \\
$30^{\circ} \mathrm{C}$ & IVG & 13,00 & & 57,14 \\
& PG & 11,58 & & 85,71 \\
& TMG & $-2,84$ & $19,21,14,9,11,15,16$ & 85,71 \\
& ISG & $-47,22$ & & 85,71 \\
$35^{\circ} \mathrm{C}$ & IVG & 13,13 & & 100,00 \\
& PG & 11,31 & & 71,43 \\
& TMG & $-6,47$ & \multirow{2}{*}{$15,14,19,1,2,11,9$} & 85,71 \\
& ISG & 3,87 & & 28,57 \\
& IVG & 20,89 & & 85,71
\end{tabular}

Com exceção para ISG em ambiente a $35^{\circ} \mathrm{C}$, coincidências foram verificadas entre as progênies selecionadas a partir da seleção direta e pelo índice de Mulamba \& Mock (1978), o que novamente denota a possibilidade do uso eficiente da seleção fenotípica em gerações iniciais de melhoramento genético em caracteres de germinação da espécie.

Em relação a biometria de sementes, as progênies de $S$. pulcherrimum apresentaram variabilidade genética significativa para todos os caracteres (Tabela 6). O conhecimento sobre a biometria é importante, pois normalmente está relacionado com as características de dispersão e com o estabelecimento de plântulas, além de ser utilizado para diferenciar espécies pioneiras e não-pioneiras em florestas tropicais (Baskin \& Baskin, 1998).

Tabela 6. Quadrado médio de genótipos (QMG), média geral, coeficiente de variação experimental $\left(C V_{e}\right)$ e estimativas de repetibilidade $(r)$ e coeficiente de determinação $\left(R^{2}\right)$ para caracteres biométricos em sementes de S. pulcherrimum.

\begin{tabular}{|c|c|c|c|c|c|c|}
\hline \multirow{2}{*}{$\begin{array}{l}\text { Caracteres } \\
\text { Biométricos }\end{array}$} & \multirow{2}{*}{ QMG } & \multirow{2}{*}{$\begin{array}{l}\text { Média } \\
\text { Geral }\end{array}$} & \multirow{2}{*}{$\begin{array}{l}C V_{e} \\
(\%)\end{array}$} & \multicolumn{3}{|c|}{$\begin{array}{l}\text { Repetibilidade via Componentes Principais e matriz de } \\
\text { covariâncias }\end{array}$} \\
\hline & & & & $\mathbf{r}$ & $\mathbf{R}^{2}$ & $\begin{array}{c}N^{\circ} \text { de avaliações para } \\
R^{2}=0,80\end{array}$ \\
\hline Peso Úmido (g) & $0,0026 * *$ & 0,061 & 18,20 & 0,420 & 0,9560 & 6 \\
\hline Comprimento (mm) & 4,7566 ** & 7,118 & 7,03 & 0,442 & 0,9596 & 5 \\
\hline Largura (mm) & $4,0330 * *$ & 4,468 & 8,11 & 0,528 & 0,9711 & 4 \\
\hline Espessura (mm) & $0,7979 * *$ & 2,963 & 10,59 & 0,227 & 0,8980 & 14 \\
\hline
\end{tabular}

$\star * ; * p<0,01, p<0,05$, respectivamente, pelo teste $\mathrm{F}$

As sementes de $S$. pulcherrimum apresentaram valores médio para o peso úmido de 0,061 $\mathrm{g}$ (variou de 0,046 a 0,081 g), comprimento de 7,11 mm (variou de 6,47 a 7,78 mm), largura de 4,47 mm (variou de 3,82 a 5,18) e espessura de 2,96 (variou de 2,68 a 3,24 mm). Devido aos elevados efeitos ambientais normalmente presentes em dados biométricos, os coeficientes de variação experimental obtidos foram considerados satisfatórios, com valores dentro do 
esperado. Além do fator genético, essas diferenças nas dimensões das sementes podem ocorrer devido ao ambiente em que estas foram produzidas. Se durante o período de maturação da semente as condições ambientais forem adversas, possivelmente as sementes originadas apresentarão desuniformidade nas dimensões e padrões morfológicos, mas isto não necessariamente terá influência no seu valor adaptativo (Lehtilä \& Ehrlén, 2005).

Considerando a avaliação de caracteres biométricos e tendo em vista a seleção daquelas progênies que apresentam as características desejáveis para futuras gerações, foi estimado o coeficiente de repetibilidade dos caracteres a fim de quantificar o número de determinações que devem ser realizadas para obter-se uma avaliação fenotípica mais eficiente. Deste modo, por meio da metodologia de componentes principais, foi obtido valores do coeficiente de repetibilidade variando de 0,227 a 0,528 para a espessura e largura das sementes, respectivamente (Tabela 6). Apesar do coeficiente de repetibilidade para espessura ter sido considerado baixo, os coeficientes de determinação, obtidos a partir das 30 repetições, para os quatro caracteres biométricos, foram superiores a $89 \%$, sugerindo que a avaliação destes pode ser realizada com alta confiabilidade.

No Centro de Sementes Nativas da Amazônia normalmente são utilizadas amostras de 30 sementes em análises biométricas para caracterização de matrizes de espécies florestais. No entanto, a fim de otimizar recursos e tempo disponível, o número de sementes amostradas pode ser reduzido para S. pulcherrimum, mantendo ainda boa acurácia na seleção de matrizes superiores. Neste caso, os resultados obtidos sugerem que para uma avaliação conjunta contemplando todos os caracteres biométricos avaliados (peso úmido, comprimento, largura e espessura) é necessária uma amostra de pelo menos 14 sementes de S. pulcherrimum para que seja realizada a seleção de matrizes superiores com acurácia de $80 \%$.

\section{CONCLUSÃO}

As progênies de $S$. pulcherrimum apresentam variabilidade genética significativa para todos os caracteres, com o aumento da temperatura promovendo um decréscimo na porcentagem e no tempo médio de germinação.

Os altos valores estimados para herdabilidade e acurácia seletiva sugerem que o valor fenotípico pode fornecer uma medida confiável para seleção de genótipos superiores, com o processo seletivo sendo mais efetivo quando praticado em cada ambiente.

Correlações significativas e no sentido favorável a seleção são obtidos para a maioria das associações entre os caracteres e ambientes considerados, tornando o processo seletivo mais simples.

As progênies 11, 14 e 15 apresentam boas características de germinação para condições de temperaturas mais amenas e elevadas, sendo indicadas para programas de conservação, melhoramento e produção de mudas da espécie.

\section{AGRADECIMENTOS}

À Coordenação de Aperfeiçoamento de Pessoal de Nível Superior (CAPES) pelo apoio financeiro na realização deste trabalho.

\section{REFERÊNCIAS BIBLIOGRÁFICAS}

Baskin, C. C., \& Baskin, J. M. (1998). Seeds: ecology, biogeography, and evolution of dormancy and germination. (666 p.). London: Academic Press.

Brasil. Ministério da Agricultura, Pecuária e Abastecimento. (2009). Regras para análise de sementes (399 p.). Brasília: Secretaria de Defesa Agropecuária. MAPA/ACS.

Brasil. Ministério da Agricultura, Pecuária e Abastecimento. (2013). Instruções para análise de sementes de espécies florestais (98р.). Brasília: Secretaria de Defesa Agropecuária, MAPA.

Carvalho, N. M., \& Nakagawa, J. (2012). Sementes: ciência, tecnologia e produção (5. ed, 590 p.). Jaboticabal: FUNEP.

Castilho, A. L., Saraceni, C. H. C., Díaz, I. E. C., Paciencia, M. L. B., \& Suffredini, I. B. (2013). New trends in dentistry: plant extracts against Enterococcus faecalis. The efficacy compared to chlorhexidine. 
Brazilian Oral Research, 27(2), 109-115. http://dx.doi.org/10.1590/S1806-83242013000100017. PMid:23538423.

Cruz, C. D. (2013). Genes - a software package for analysis in experimental statistics and quantitative genetics. Acta Scientiarum, 35(3), 271-276.

Cruz, C. D., Carneiro, P. C. S., \& Regazzi, A. J. (2014). Modelos biométricos aplicados ao melhoramento genético. (3. ed., Vol. 2, 668 p.). Viçosa: Ed. UFV.

Duarte, M. M., Milani, J. E. F., Blum, C. T., \& Nogueira, A. C. (2015). Germinação e morfologia de sementes e plântulas de Albizia edwallii (Hoehne) Barneby \& J. W. Grimes. Revista Caatinga, 28(3), 166-173. http://dx.doi.org/10.1590/1983-21252015v28n319rc.

Freitas, V. L. O., Viegas, F. P., \& Lopes, R. D. M. F. (2013). Biometria de frutos e sementes, germinação e desenvolvimento inicial de Barbatimão (Stryphnodendron adstringens). Floresta, 44(1), 21-32. http://dx.doi.org/10.5380/rf.v44i1.32265.

Lehtilä, K., \& Ehrlén, J. (2005). Seed size as an indicator of seed quality: a case study of Primula veris. Acta Oecologica, 28(3), 207-212. http://dx.doi.org/10.1016/j.actao.2005.04.004.

Lemus Filho, J. P., Guerra, S. T. M., Lovato, M. B., \& Scotti, M. R. M. M. L. (1997). Germinação de sementes de Senna macranthera, Senna multijuga e Stryphnodendron polyphyllum. Pesquisa Agropecuária Brasileira, 32(4), 357-361.

Lima Júnior, M. J. V. (2016). Manejo de sementes para o cultivo de espécies florestais da Amazônia. São Paulo: Editora Brasil Seikyo Ltda.

Lins Neto, J. D. R., Uchôa, A. D. A., Moura, P. A., Bezerra Filho, C. M., Tenório, J. C. G., Silva, A. G., Ximenes, R. M., Silva, M. A. V., \& Correia, M. T. S. (2016). Phytochemical screening, total phenolic content and antioxidant activity of some plants from Brazilian flora. Journal of Medicinal Plants Research, 10(27), 409-416.

Lorenzi, H. (1992). Árvores brasileiras: manual de identificação e cultivos de plantas arbóreas do Brasil (pp. 189-192). Nova Odessa, SP: Editora Plantarum.

Martins, C. C., Machado, C. G., \& Nakagawa, J. (2008). Temperatura e substrato para o teste de germinação de sementes de barbatimão (Stryphnodendron adstringens (Mart.) Coville (Leguminosae). Revista Árvore, 32(4), 633-639. http://dx.doi.org/10.1590/S0100-67622008000400004.

Monteiro, D., \& Ramalho, M. (2010). Abelhas generalistas (Meliponina) e o sucesso reprodutivo de Stryphnodendron pulcherrimum (Fabales: Mimosaceae) com florada em massa na Mata Atlântica, BA. Neotropical Entomology, 39(4), 519-526. http://dx.doi.org/10.1590/S1519-566X2010000400009. PMid:20877986.

Mulamba, N. N., \& Mock, J. J. (1978). Improvement of yield potential of the Eto Blanco maize (Zea mays L.) population by breeding for plant traits. Egyptian Journal of Genetics and Cytology, 7, 40-57.

Nascimento Júnior, L. G. L., Lopes, M. T. G., Valente, M. S. F., Martins, C. C., Colares, C. R. B., \& Lima Júnior, M. J. V. (2016). Estimativa de parâmetros genéticos em sementes de caroba. Revista de Ciências Agrárias (Belém), 59(4), 311-319. http://dx.doi.org/10.4322/rca.2153.

Pereira, A. G., Cruz, E. D., \& Barros, H. S. D. (2016). Methods for overcoming dormancy in Stryphnodendron pulcherrimum seeds. Pesquisa Florestal Brasileira, 36(87), 195-199. http://dx.doi.org/10.4336/2016.pfb.36.87.931.

Resende, M. D. V. (2007). Matemática e estatística na análise de experimentos e no melhoramento genético (535 p.). Colombo: Embrapa Florestas.

Rickli, H. C., Nogueira, A. C., Koehler, H. S., \& Zuffellato-Ribas, K. C. (2014). Germinação de sementes de Vochysia bifalcata em diferentes substratos e temperaturas. Floresta, 44(4), 669-676. http://dx.doi.org/10.5380/rf.v44i4.33688.

Rodrigues, E. R., Hirano, E., \& Nogueira, A. C. (2008). Germinação de sementes de pessegueiro-bravo sob diferentes condições de luz e substrato. Scientia Agraria, 9(1), 91-94. http://dx.doi.org/10.5380/rsa.v9i1.10142.

Santana, D. G., \& Ranal, M. A. (2000). Análise estatística na germinação. Revista Brasileira de Fisiologia Vegetal, 12, 205-237.

Santos, L. S., Cabral, G. P., \& Costa, R. R. G. F. (2014). Variabilidade genética entre e dentro de progênies de ipê rosa (Handroanthus avellanedae (Lorentz ex Griseb.) Mattos (Bignoniaceae). Global Science Technology, 7(2), 98-105. http://dx.doi.org/10.14688/1984-3801/gst.v7n2p98-105.

Silva, C. A., Teixeira, A. L., Rocha, R. O., Baptista, A. C., \& Silva, A. A. S. (2015). Effect of temperature and pre-germination treatments on seed germination of juerana branca (Stryphnodendron 
pulcherrimum). African Journal of Agricultural Research, 10(6), 494-498.

http://dx.doi.org/10.5897/AJAR2014.8834.

Souza-Moreira, T. M., Queiroz-Fernandes, G. M., \& Pietro, R. C. L. R. (2018). Stryphnodendron species known as "Barbatimão": a comprehensive report. Molecules, 23(4), e.910.

Tomaz, J. S., Lopes, M. T. G., Valente, M. S. F., Lima Júnior, M. J. V., Muniz, G. I. B., \& Rosado, S. I. P. (2018). Genetic evaluation of seed germination and development of seedlings in Ormosia excelsa Benth. Floresta, 48(3), 331-342. http://dx.doi.org/10.5380/rf.v48i3.52799.

Valente, M. S. F., Lopes, M., Chaves, F. C. M., Oliveira, A. M., \& Freitas, D. R. B. (2017). Repeatability of biometric and fruit and seed yield traits of sacha inchi. Acta Amazonica, 47(3), 195-202. http://dx.doi.org/10.1590/1809-4392201602623.

Contribuição dos Autores: INLS: conceituação, obtenção de financiamento, administração do projeto, investigação, escrita - primeira redação; MTGL: conceituação, obtenção de financiamento, supervisão, metodologia, administração do projeto, validação; MSFV: metodologia, supervisão, curadoria de dados, análise formal, escrita - revisão e edição; MJVLJ: metodologia, supervisão, curadoria de dados, validação; TJPF: metodologia, supervisão, visualização, validação. 